\title{
PENGEMBANGAN MULTIMEDIA INTERAKTIF GEOGRAFI KELAS X MATERI TATA SURYA
}

\author{
Nanda Kresna Putra Pratama, Eka Pramono Adi, Saida Ulfa \\ Jurusan Teknologi Pendidikan, Fakultas Ilmu Pendidikan, Universitas Negeri Malang \\ Jalan Semarang 5 Malang 65145 0341-574700 \\ Nandakresna2@gmail.com
}

\section{Article History}

Received: 1 September 2020, Accepted: 26 November 2020, Published: 28 Mei 2021

\begin{abstract}
Abstrak
Multimedia interaktif materi tata surya merupakan media yang digunakan sebagai suplemen untuk memunculkan semangat siswa saat proses pembelajaran. Pemanfaatan multimedia tersebut bisa dipakai secara berulang kali, sehingga materi yang disampaikan dapat dimengerti oleh siswa. Penggunaan metode yaitu model Lee \& Owens yang memiliki lima langkah yaitu: Analisis, Desain, Pengembangan, Implementasi dan Evaluasi. Tujuan pengembangan multimedia interaktif ini untuk membantu memudahkan proses pembelajaran. Menurut ahli, media dan ahli materi multimedia interaktif memberikan tanggapan bahwa multimedia interaktif layak digunakan. Dalam uji coba lapangan pada siswa SMA Pawyatan Daha Kediri kelas X IPS 1 mengalami peningkatan nilai saat menggunakan multimedia interaktif dan dapat disimpulkan bahwa multimedia interaktif geografi materi tata surya merupakan solusi bagi guru untuk diterapkan kepada siswa saat mengajar di SMA Pawyatan Daha.
\end{abstract}

Keyword: Masukkan 3-5 kata kunci Anda dalam Bahasa Indonesia; kata kunci dipisahkan dengan titik koma

\begin{abstract}
The interactive multimedia material of the solar system is a medium that is used as a supplement to bring out the enthusiasm of students during the learning process. The use of multimedia can be used repeatedly, so that the material presented can be understood by students. The development method used is the Lee \& Owens model which has five steps, namely: Analysis, Design, Development, Implementation and Evaluation. The purpose of developing interactive multimedia is to help facilitate the learning process. According to media experts and material experts the results of this study indicate that interactive multimedia is suitable for use. In field trials on Pawyatan Daha Kediri high school students class X IPS 1, the value increases when using interactive multimedia and it can be concluded that interactive multimedia geography solar system material is a solution for teachers to be applied to students while teaching at Pawyatan Daha High School.
\end{abstract}

Keyword: Put 3-5 your keywords here in Bahasa Indonesia; keywords separated by semicolon 


\section{PENDAHULUAN}

Kemajuan teknologi merupakan salah satu faktor yang turut menunjang usaha pembaharuan. Peranan teknologi begitu menonjol terutama pada masyarakat di negara-negara berkembang. Pemerintah dan masyarakat memberikan perhatian secara maksimal terhadap perkembangan teknologi, karena mereka menyadari peranan dan fungsi teknologi itu bagi kehidupan mereka. Teknologi informasi dan komunikasi salah satu produknya berupa software. Produk tersebut mempengaruhi berbagai sektor termasuk pendidikan. Pemanfaatan produk untuk kegiatan pembelajaran sangat diperlukan. Produk tersebut berupa multimedia pembelajaran yang merupakan media pembelajaran. Karena media pembelajaran merupakan alat yang dibuat untuk membantu guru saat menyampaikan materi yang bersifat abstrak (Criticos, 1996).

Penggunaan perangkat komputer untuk mengombinasikan tiulisan, grafik, suara, gambar animasi (video) menjadi satu dengan link dan tool yang benar sehingga berpotensi pengguna multimedia dapat melakukan akses navigasi,berinteraksi, berkarya, dan berkomunikasi (Sarwiko, 2010). Metode pembelajaran dimana penyampaian materi, diskusi, dan kegiatan pembelajaran lain dilakukan melalui media komputer dan bersifat dua arah disebut metode pembelajaran multimedia interaktif (Biesta, Gert, 1996). Multimedia pembelajaran merupakan sebuah multimedia yang berisikan langkah-langkah pembelajaran yang di disain sebagus mungkin agar pengguna aktif dan tertarik dalam proses pembelajarannya. (Kurniadi, 2013). Interaktivitas adalah keunggulan dari multimedia, dimana pengguna berinteraksi dengan materi atau media. Di dalam multimedia interaktif, pengguna dapat mengendalikan bagian-bagian dari struktur multimedia yang ditampilkan menurut Vaughan (2004).

Sadiman (2006) berpendapat media ialah kata dari bahasa latin yaitu medius, yang secara harafiah berarti 'perantara'. Sehingga, media bisa diartikan sebagai perantara atau pengantar pesan dari pengirim ke penerima pesan. Berdasarkan pendapat tersebut, penggunaan media dalam pembelajaran memberikan keuntungan bagi guru maupun siswa. Melalui pemanfaatan media dapat meningkatkan efektifitas dalam mencapai tujuan. Guru memiliki sarana yang cukup memadai dan bagi siswa, penggunaan media dapat membuat siswa mengatasi kebosanan dan kejenuhan pada saat menerima pelajaran. Media pembelajaran yang memuat berbagai media digital disebut dengan media pembelajaran berbasis multimedia. Multimedia pembelajaran menyajikan bahan pelajaran dalam bentuk arahan dan penjelasan dengan sistem komunikasi interaktif stimulus respon, ditampilakn secara struktural, dan sistematis sesuai dengan kurikulum yang berlaku.

Sebuah sistem dimana letak media adalah sebagai elemen dari sistem pembelajaran disebut proses pembelajaran. Tanpa adanya media, komunikasi dalam pembelajaran tidak akan terjadi dan proses pembelajaran tidak akan berlangsung. Multimedia pembelajaran adalah komponen integral dari sistem pembelajaran (Praherdiono \& Adi 2008). Geografi merupakan ilmu yang mempelajari persamaan dan perbedaan fenomena geosfer dengan sudut pandang kelingkungan dan kewilayahan dalam konteks keruangan. Mengutip pendapat (James Preston E., 1959).dalam bukunya A Geography Of Man. Geography is Mother Science diartikan geografi juga disebut ilmu ibu (induk), karena banyak sektor pembelajaran yang dimulai dengan pengamatan wajah (muka) bumi yang sebenarnya beralih untuk mempelajari proses-proses tertentu di mana pun mereka berada.

Berdasarkan observasi yang dilakukan di SMA Pawyatan Daha Kediri proses pembelajaran geografi materi tata surya selama mengajar guru masih menggunakan metode lisan dan masih terpaku pada buku pegangan. Pada proses pembelajaran yang sedang berlangsung banyak siswa yang tidak fokus terhadap pelajaran, sehingga proses pembelajaran tidak berjalan secara efektif. Dengan adanya keadaan tersebut, hal ini menjadi pemicu munculnya permasalahan di dalam proses pembelajaran yang kurangnya variasi media dalam pembelajaran yang digunakan sehingga suasana saat proses terjadinya pembelajaran menjadi monoton yang menimbulkan siswa tidak tertarik dan tidak fokus terhadap pelajaran. 
Berdasarkan permasalahan di atas, bahwa perlu adanya inovasi dari multimedia interaktif agar dapat membantu lancarnya perjalanan pembelajaran agar bisa digunakan menarik daya perhatian siswa saat pelajar. Multimedia interaktif merupakan gabungan berbagai media dari tulisan, gambar, suara, video, animasi dan interaktivitas. Keterlibatan berbagai indera saat proses belajar dapat melancarkan siswa dalam hal memperoleh ilmu. Semakin banyak indera yang terlibat dalam proses belajar, maka proses belajar tersebut akan menjadi lebih efektif (Novita et al., 2016). Penelitian yang dilakukan oleh Dede et al., (2019) menghasilkan produk multimedia interaktif untuk siswa Tuna Grahita kelas 6C SLBS BCG Idayu Kota Malang pada pembelajaran Tema Tanah. Berdasarkan hasil uji coba kelayakan oleh ahli media dan materi produk dinyatakan layak sebagai media pembelajaran. Ketika multimedia diuji cobakan dikatakan tepat untuk dipegunakan pada jalannya pembelajaran yang menarik dan membangkitkan motivasi dalam penyampaian materi pembelajaran sehinga tidak merasakan bosan dan menyenangkan. Penelitian lain yang dilakukan Arianda et al., (2019) menghasilakan multimedia interaktif pembelajaran pada pelajaran Ilmu Pengetahuan Sosial kelas VII SMP Plus Fityani Pujon dengan hasillayak untuk proses pembelajaran.

Tujuannya adalah menciptakan produk atau barang atau produk multimedia interaktif pada pelajaran Geografi materi Tata Surya yang menarik, asik dan layak untuk dipergunakan saat mengajar di kelas. Dengan demikian produk yang dikembangakan diharapkan dapat memperlancar prosses penciapaian materi pembelajaran kepada siswa, membuat siswa lebih berpartisipasi secara langsung dalam pembelajaran yang pusatnya di siswa, menarik perhatian siswa, menumbuhkan motivasi belajar, interaktif, menyenangkan dan siswa telibat langsung dalam proses pembelajaran.

\section{METODE}

Metode dalam penelitian ini menerapkan metode penelitian pengembangan. Model yang diterapkan di penelitian ini memakai model pengembangan dari (Lee \& Owens, 2004). Metode tersebut digunakan karena memiliki prosedur yang sesuai untuk mengembangkan multimedia pembelajaran dengan setiap langkahnya tersusun secara sistematis dan pola pengembangan yang jelas. (Lee \& Owens, 2004) menyatakan terdapat lima langkah dalam proses pengembangan sebagai berikut: Analisis (Assesment), Desain (Design), Pengembangan (Development), Implementasi (Implementation), dan Evaluasi (Evaluation) seperti yang terlihat pada gambar 1.

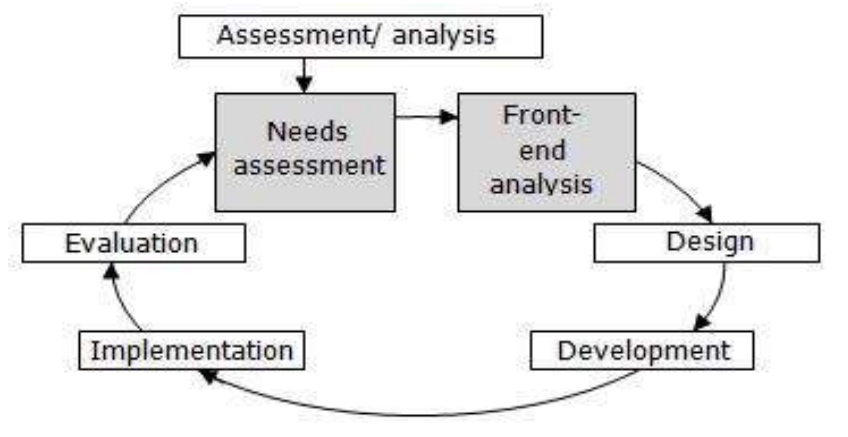

Gambar 1. Model Penelitian Pengembangan Lee \& Owens

Angket dipakai untuk mengumpulkan data dari ahli media dan materi. Instrumen yang digunakan untuk pengumpulan data dalam pengembangan ini yaitu berupa angket. Angket merupakan pertanyaan-pertanyaan yang tertulis lalu dipakai untuk memperoleh informasi dari responden Arikunto (2009). Pertimbangannya adalah angket dapat memperoleh data yang banyak dalam waktu yang singkat, tenaga yang diperlukan sedikit dan responden bebas untuk menjawab tanpa pengaruh prang lain. Alasan penggunaan angket dengan pertimbangan dalam kurun waktu yang cepat atau singkat bisa mendapatkan data yang begitu banyak, tenaga yang diperlukan sedikit dan responden dapat menjawab dengan bebas tanpa pengaruh orang lain.

Menurut Lee \& Owen analisis data dilakukan dalam rangka memecahkan masalah yang ditemui. Dari mengidentifikasi sumber informasi, mengumpulkan informasi dan bahan-bahan dalam pembelajaran, mengevaluasi informasi berdasarkan tujuan, pembelajar dan kebutuhan. Dalam pengembangan media interaktif, analisa data menggunakan instrumen ahli materi, ahli media, dan audiens. 
Analisis data angket dalam pengembangan ini tergolong jenis data kualitatif (angket) digunakan analisis deskriptif kualitatif. Angket digunakan untuk menghitung data angket dari tanggapan ahli media, ahli materi dan siswa. Tes hasil belajar termasuk dalam jenis data kuantitatif sehingga teknik analisis datanya menggunakan deskriptif kuantitatif.

\section{HASIL}

Need Assessment atau analisis kebutuhan ditempuh dengan cara wawancara dan observasi secara terjun kelapangan untuk mengetahui keadaan atau situasi sekolah. Hal ini bertujuan untuk melihat permasalahan yang ada di sekolah. Multimedia interaktif ini perlu untuk pembelajaran di dalam kelas mengingat permasalahan yang terjadi, yaitu metode pembelajaran yang monoton sehingga kurang menarik bagi siswa berdasarkan hasil observasi langsung di sekolah.

Front-End Analysis dilakukan untuk mendapatkan informasi yang lebih lengkap dan detail untuk media yang dikembangkan. Tahapan ini menganalisis karakteristik siswa, ketersediaan teknologi, situasi, kondisi pada ssekolah untuk memperoleh gambaran tentang pengembangan yang dilakukan. Sehingga dapat menentukan tujuan pembelajaran dan mengurangi kerumitan saat penggunaan media yang dikembangkan.

Pada tahap Design dikembangkan dengan acuan pada teori Mayer (2001) yaitu : prinsip multimedia, keterdekatan ruang, keterdekatan waktu, koherensi, modalitas belajar, redudansi, dan interaktivitas. Desain multimedia interaktif terdapat menu utama, yaitu menu materi yang di dalamnya ada 4 sub menu materi yang meliputi menu "tata surya" yang menjelaskan seperti apa tata surya itu, menu "planet" yang menjelaskan pengertian sebuah planet, menu "klasifikasi" planet yaitu menjelaskan pembagian planet berdasarkan massan dan jaraknya, terakhir menu "planet-planet" yang menggambarkan susunan tata surya.

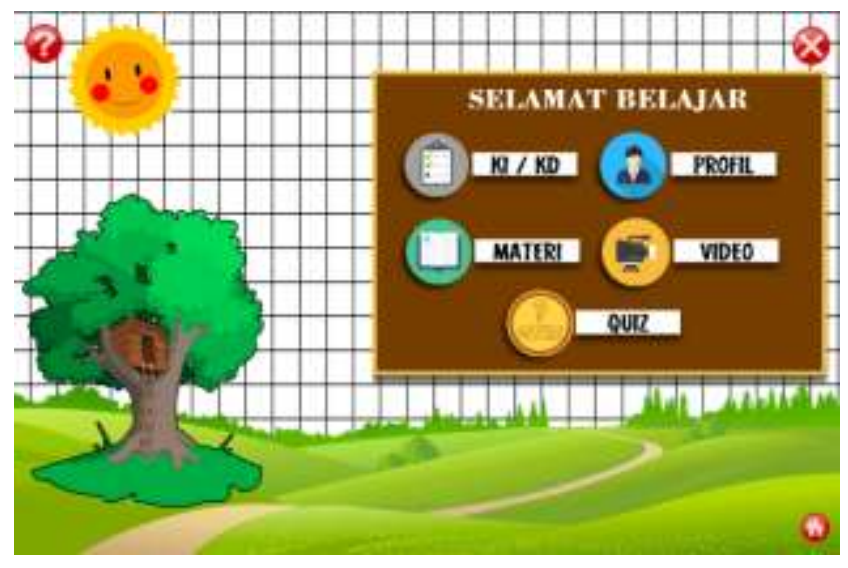

Gambar 2. Tampilan Menu Utama

Pada tahapan Development atau pengembangan multimedia interaktif meggunakan software utama untuk pembuatan, yaitu lectora inspire 17. Software pendukung dalam pengembangan adalah Adobe Photoshop CS4 untuk mengolah gambar.

Pada tampilan menu utama seperti gambar 2 memiliki 5 pilihan menu yaitu KI/KD yang merupakan menu Kompetensi Inti dan Kompetensi Dasar, menu Profil yang merupakan menu dari profil si pengembang multimedia tersebut, menu Materi yang berisikan 4 jenis materi di dalamnya,

Isi dari menu materi terdiri dari menu "tata surya" yang menjelaskan seperti apa tata surya itu, menu "planet" yang menjelaskan pengertian sebuah planet, menu "klasifikasi" planet yaitu menjelaskan pembagian planet berdasarkan massan dan jaraknya, terakhir menu "planet-planet" yang menggambarkan susunan tata surya seperti gambar 3. 


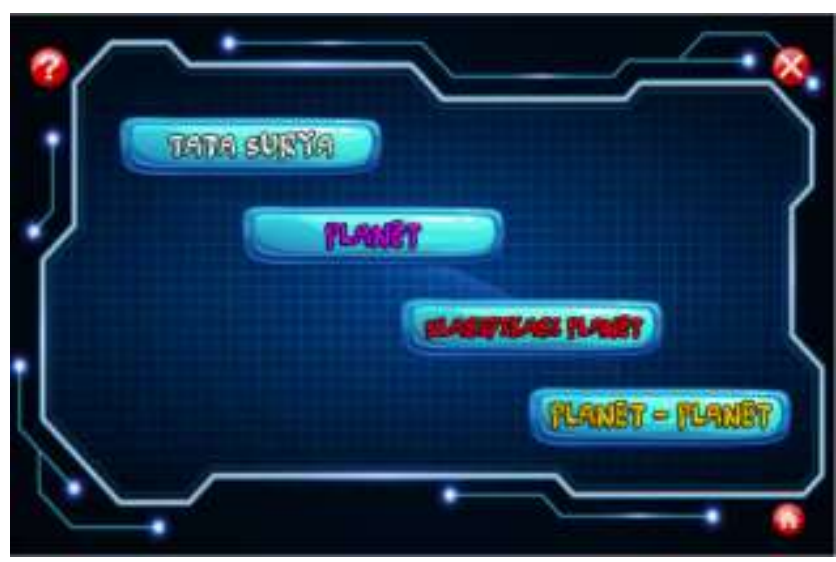

Gambar 3. Tampilan Menu Materi

Hasil review ahli media mendapatkan rata-rata nilai sebesar 3,80 dari rata-rata nilai yang diharapkan sebesar 4,00. Terdapat 12 pertanyaan yang mendapatkan nilai 4, dan 3 pertanyaan mendapatkan nilai 3 seperti yang terlihat pada gambar 4. Sehingga multimedia interaktif geografi materi tata surya mendapat respon positif dan layak digunakan. Ahli media memberikan komentar bahwa secara umum media layak untuk penelitian. Saran untuk optimalisasi, dalam video perlu ditambahkan informasi alamat link atau web jika video tersebut hasil dari mengunduh.

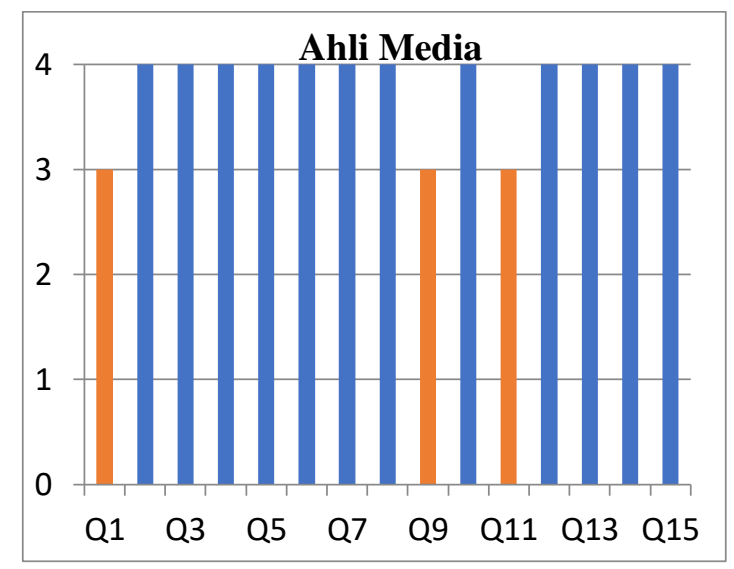

Gambar 4. Hasil Review Ahli Media

Berdasarkan gambar 5 di atas hasil dari review ahli materi nilai rata-rata yang diperoleh sebesar 3,90 dari nilai rata-rata yang di harapkan sebesar 4,00. Terdapat 9 pertanyaan yang dapat nilai 4, dan 1 pertanyaan mendapatkan nilai 3. Sehingga materi yang terkandung dalam multimedia interaktif mendapatkan respon positif dan layak digunakan. Ahli materi berkomentar bahwa multimedia interaktif ini sangat membantu dalam proses pembelajaran dan sesuai dengan tingkat perkembangan anak sehingga pembelajaran lebih menarik. Saran dari ahli materi hanya pada kelengkapan materi yang terdapat dalam multimedia interaktif karena yang tercantum hanya materi dasar. 


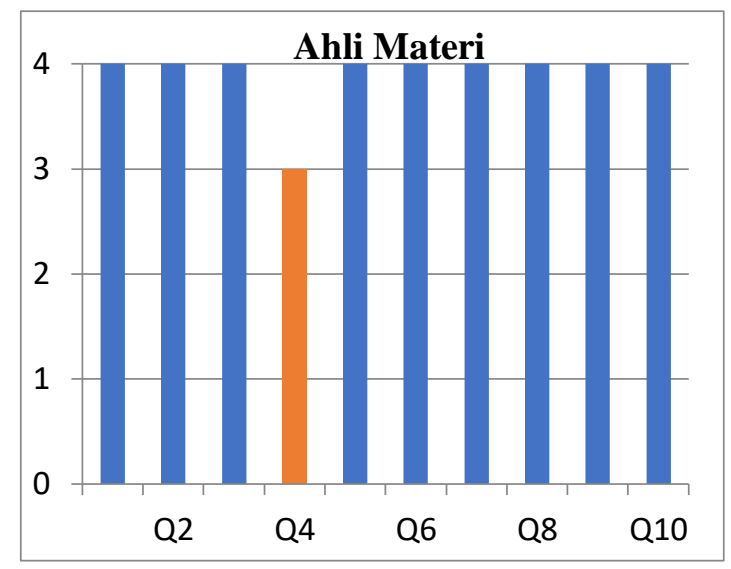

Gambar 5. Hasil Review Ahli Materi

\section{PEMBAHASAN}

Multimedia interaktif ini telah melalui review oleh, ahli materi dan ahli media. Hasil review ahli materi Q4 tentang kelengkapan materi sudah selaras dengan kompetensi dasar mendapatkan nilai 3. Hal ini dikarenakan materi yang terdapat pada multimedia interaktif terbatas namun secara keseluruhan tujuan pembelajaran sudah selaras dengan kompetensi dasar yang terdapat pada kurikulum sekolah menengah atas. Hasil review ahli materi keseluruhan mendapatkan respon positif dan dinyatakan layak tanpa revisi.

Kemudian hasil dari review ahli media juga mendapatkan nilai tinggi sebesar 3,80. Terdapat 12 pertanyaan yang mendapatkan nilai 4 dan 3 pertanyaan yang mendapat nilai 3. Q1 yang mendapatkan nilai 3 adalah tentang ketepatan pemilihan background dengan materi, karena perlu penyesuaian lagi agar tampilan lebih selaras antara background dengan materi terlihat sesuai. Q9 yang mendapatkan nilai 3 tentang kesesuaian animasi dengan materi, hal ini sama seperti Q1 yang perlu diselaraskan antara animasi dengan materi. Kemudian Q11 ketepatan pemilihan video dengan materi yang mendapatkan nilai 3, jika video mengunduh dari internet alangkah baiknya link video yang diunduh ikut dicantumkan. Secara keseluruhan hasil tersebut menunjukkan bahwa Multimedia Interakti materi Tata Surya telah memenuhi hampir seluruh aspek review ahli media sehingga mendapat respon positif. Dengan ini multimedia interaktif yang dikembangkan sudah layak untuk digunakan dan diterapkan pada prose pembelajaran.

Selain hasil penilaian, para ahli juga memberikan beberapa komentar dan saran. Ahli materi berkomentar multimedia interakitf ini sangat membantu dalam jalannya pembelajaran dan selaras dengan tingkat perkembangan anak akhirnya pembelajaran lebih menarik. Saran dari ahli materi hanya pada kelengkapan materi yang terdapat dalam multimedia interaktif karena yang tercantum hanya materi dasar. Ahli media memberikan komentar bahwa secara umum media layak untuk penelitian. Saran untuk optimalisasi, dalam video perlu ditambahkan informasi alamat link atau web jika video tersebut hasil dari mengunduh.

Permasalahan yang sering muncul dalam pembelajaran adalah guru hanya menggunakan metode konvensional sehingga pembelajaran kurang menarik, terlihat monoton dan suasana didalam kelas jadi membosankan. Namun dari pada itu tujuan pembelajaran belum tercapai dengan optimal. Agar tujuan pembelajaran dapat dilampaui dengan optimal, maka pembelajaran harus dikemas dengan inovatif, menarik, dan menyenangkan (Andrijati, 2014). Pembelajaran yang inovatif, menarik dan menyenangkan dapat dilakukan dengan memanfaatkan multimedia interaktif (Darojat et al., 2016). Multimedia interaktif memberi tampilan unik dalam pembelajaran pada akhirnya lebih menyenangkan dan tidak menimbulkan bosan, karena selama berjalannya kegiatan mengajar membuat peserta didik lebih antusias 
dalam mengikuti proses pembelajaran dan tidak membosankan (Novianto et al., 2019). Hal tersebut didukung oleh penelitian yang memperlihatkan bahwa multimedia interaktif menimbulkan adanya ketertarikan dan adanya rasa senang serta tertarik saat mengikuti peelajaran (Iswara, 2020). Seperti yang telah dijelaskan oleh Alessi \& Trollip (2001) bahwa multimedia memiliki berbagai keuntungan terutama dalam memotivasi siswa sehingga dapat meluangkan waktu lebih banyak untuk belajar karena dapat digunakan untuk membuat pembelajaran lebih menyenangkan.

Multimedia interaktif pembelajaran sangat berguna sebagai penghubung antara siswa dan guru untuk membantu proses belajar mengajar (Mustaqim, 2016). Dalam pemilihan multimedia pembelajaran perlu diketahui tujuan, manfaat maupun fungsi dari multimedia pembelajaran yang dipakai sebagai bahan pertimbangan dan juga menentukan jenis multimedia yang digunakan dalam proses pembelajaran di kelas. Fungsi media dalam kegiatan pembelajaran merupakan bagian yang sangat menentukan efektifitas dan efisiensi pencapaian tujuan pembelajaran dari penelitian yang sudah dilakukan oleh Armansyah et al., (2019). Multimedia memiliki beberapa fusngsi, yaitu memudahkan belajar bagi siswa serta guru, memberikan pengalaman lebih nyata (yang abstrak dapat menjadi konkret), menarik perhatian siswa lebih besar (proses pembelajran tidak membosankan), menarik perhatian serta minat siswa dalam proses pembelajaran dan dapat membangkitkan dunia teori dengan realita (Wiyono, 2012).

Geografi merupakan ilmu kajian yang luas yang mempelajari geosfer yang bersifat sosial dan fisik (Jatmiko et al., 2018). Materi tata surya termasuk pada geografi fisik yang berluang lingkup pada astronomi atau kadang disebut ilmu bintang. Astronomi yaitu sebuah ilmu yang meneiliti benda langit serta fenomena-fenomena alam yang terjadi diluar ruang lingkup atmosfer bumi. Dengan demikian materi pokoknya adalah mempelajari mempelajari berbagai sisi dan benda langit seperti asal usul, sifat fisika atau kimia, meteorologi, dan gerak, serta bagaimana pengetahuan benda-benda tersebut, menjelaskan pembentukan dan perkembangan alam semesta.

Fungsi multimedia tidak hanya sekedar sebagai alat bantu dalam mengomunikasikan materi pembelajaran saja tetapi juga berfungsi secara efektif dalam konteks pembelajaran yang berlangsung tanpa menuntut kehadiran guru (Miftah, 2013). Dari hasil yang didapat saat memakai multimedia interaktif antara lain: Proses belajar lebih menarik perhatian siswa sehingga dapat memunculkan semangat dan motivasi belajar, Materi yang di sampaikan dalam pembelajaran terlihat lebih jelas sehingga dapat dipahami dengan mudah oleh siswa, Penggunaan metode dalam proses pembelajaran lebih bervariasi, komunikasi tidak hanya secara lisan melalui penyampaian materi oleh guru, sehingga konsentrasi siswa tidak terpecah dan bosan serta tenaga guru pun juga tidak terkuras habis pada peroses pembelajaran tersebut, Siswa lebih aktif dan respon ketika proses kegiatan belajar, karena tidak mendengarkan penjelasan secara lisan dari guru, namun juga melakukan aktivitas lain seperti mencermati dan menoperasikan (Sudjana, 1991). Selain menciptakan motivasi dan rasa minat siswa, multimedia interaktif mampu meningkatkan pemahaman, prestasi belajar dan menampilkan data dengan lebih menarik dan terpercaya, memberi kemudahan dalam menafsirkan data dan informasi (Tafonao, 2018).

Mekanisme pengembangan multimedia interaktif ini memakai model pengembangan Lee \& Owens dengan langkah-langkah pengembangan sebagai berikut: Penilaian kebutuhan dan analisis, Desain, Pengembangan, Implementasi, dan Evaluasi. Menurut (Lee \& Owens, 2004), langkah awal dalam pengembangan multimedia adalah mengambil cara yang sistematis untuk menetukan apa yang dibutuhkan dan memberikan soluisi sesuai dengan kebutuhan. Pada saat ini sudah dilakukan analisis kebutuhan diseekolah dengan melihat proses belajaar yang sudah disusun di kelas dan memberikan solusi belajar dengan multimedia interaktif untuk mata pelajaran geografi pada materi tata surya. Setelah mendapat hasil dari ahli media, ahli materi dan audien, maka dilakukan penyempurnaan terhadap kelemahan-kelemahan yang ada dalam multimedia interaktif. 
Adapun kelebihan dari multimedia interaktif yaitu mudah dioperasikan untuk siswa sekolah menengah atas, tidak membutuhkan waktu yang lama dalam penggunaanya, media bersifat interaktif sehingga siswa mendapatkan balikan secara langsung, dilengkapi dengan petunjuk pemanfaatan, dan kuis atau soal latihan tampilan media disesuaikan dengan karakteristik siswa dengan penggunaan penebalan kata, gambar-gambar bergerak dan video yang dapat membuat siswa paham dan termotivasi untuk belajar (Rorita et al., 2018). Sedangkan kekurangan media ini yaitu media hanya terbatas sampai pokok materi tata surya.

Dalam multimedia interaktif ini, materi ditampilkan dengan menggunakan gambar-gambar planet. Materi diawali dengan memberikan pengertian tata surya serta, pengertian planet-planet, klasifikasi planet dan beserta karakteristiknya. Penggunaan gambar, simbol dan warna mendominasi dalam media ini. Penggunaan warna cerah mampu menarik perhatian agar lebih focus untuk belajar dan memudahkan siswa untuk mengingat. Karakteristik produk hasil pengembangan adalah sebuah software multimedia interaktif sebagai alternatif dalam memudahkan siswa untuk mengenal dan memahami tata surya serta membantu guru dalam mengefektifkan proses pembelajaran. Paket produk multimedia pembelajaran interaktif yang dihasilkan sebagai produk pengembangan ini terdiri dari CD (Compact Disk) alternatif yang telah dilengkapi dengan audio, dan petunjuk pemanfaatan.

\section{SIMPULAN}

Karakteristik produk dari hasil pengembangan ini adalah produk multimedia interaktif yang bisa untuk dijadikan alternatif agar memudahkan siswa dalam belajar mengenal dan memahami tata surya serta membantu guru untuk mengefektifkan proses pembelajaran. Paket produk multimedia pembelajaran interaktif yang dihasilkan sebagai produk pengembangan ini terdiri dari CD (Compact Disk) alternatif yang telah dilengkapi dengan audio, dan petunjuk pemanfaatan. Sebagai saran untuk kedepannya mudah-mudahan penelitian ini multimedia interaktif dengan tema yang lain dan menciptakan sebuah produk multimedia yang lebih baik, serta alternatif untuk mengembangkan materi yang sama dengan konsep yang berbeda dan animasi yang lebih menarik.

\section{DAFTAR RUJUKAN}

Sadiman, A.S. (2006). Media Pendidikan: Pengertian, Pengembangan dan Pemanfaatannya. Jakarta: CV Rajawali.

Alessi, S. M., Trollip, S. R. (2001). Multimedia for Learning: Methods and Development. Massachusetts: A Pearson Education. University of Lowa \& Capella University

Andrijati, N. (2014). Penerapan Media Pembelajaran Inovatif Dalam Pembelajaran Matematika Sekolah Dasar di PGSD UPP Tegal. Jurnal Penelitian Pendidikan, 31 (2) 123-132. Retrieved from https://journal.unnes.ac.id/nju/index.php/JPP/article/view/5696

Arianda, F. D. (2016). Pengembangan Multimedia Pembelajaran Interaktif Ilmu Pengetahuan Sosial SMP. Development Of Interactive Multimedia Learning Social Science SMP. Jurnal Inovasi dan Teknologi Pembelajaran, 2 (1) 302-306. Retrieved from http://journal2.um.ac.id/index.php/jinotep/article/view/2176/1280

Arikunto, S. (2009). Prosedur Penelitian Suatu Pendekatan Praktik. Edisi Revisi 6. Jakarta : Rineka Cipta.

Armansyah, F. (2019). Multimedia Interaktif Sebagai Media Visualisasi Dasar-Dasar Animasi. Jurnal Kajian Teknologi Pendidikan, 2 (3) 224-229. Retrieved from http://journal2.um.ac.id/index.php/jktp/article/view/8283/4366

Biesta, G. (Ed). (1996). Education Communication: The Two Faces of Communicative Pedagogy, In A. Neiman, Philosophy of Education, 1995, (pp. 185-194). Urbana, III: Philosophy of Education Society. 
Criticos, C . (1996). Media Selection. In Plomp, T., \& Ely, D. P.(Eds), International Encyclopedia of Educational Technology. New York: Elsevier Science, Inc.

Darojat, A. (2016). Pengembangan Multimedia Pembelajaran Interaktif Pada Mata Pelajaran Ilmu Pengetahuan Alam Untuk Siswa Kelas VIII SMP. Jurnal Inovasi dan Teknologi Pembelajaran, 2 (2) 297-301. Retrieved form http://journal2.um.ac.id/index.php/jinotep/article/view/2175/1279

Herdiyanto, D. M., Sulton, Praherdiono, H. (2009). Pengembangan Multimedia Pembelajaran Interaktif Pada Materi Tema Tanah Bagi Siswa Tunagrahita. Jurnal Kajian Teknologi Pendidikan, 3 (1) 88 96. Retrieved from http://journal2.um.ac.id/index.php/jktp/article/view/10907

Iswara, G. P. S., Kuswandi, D., Husna, A. (2020). Pengembangan Multimedia Interaktif Dilengkapi Dengan Simulasi Untuk Memvisualkan Reaksi Kimia Pada Materi Larutan Penyangga SMA Kelas XI. Jurnal Inovasi Teknologi Pembelajaran, (6) 2 58-68. Retrieved from http://journal2.um.ac.id/index.php/jinotep/article/view/7451/5663

James, P. E. (1959). Geography is Mother Science A Geography Of Man. Syracuse University, New York.

Jatmiko, A. G., Toenlioe, A. JE., Soepriyanto, Y. (2018). Pengembangan WebQuest Sebagai Bahan Ajar Keragaman Indonesia dan Interaksi Global. Jurnal Kajian Teknologi Pendidikan, 1 (4) 321-326. Retrieved from http://journal2.um.ac.id/index.php/jktp/article/view/6983/3861

Kurniadi, A. (2013). Pengembangan Multimedia Pembelajaran Pada Mata Pelajaran TIK Kelas XI di Madrasah Aliyah Negeri Mendoyo. Jurnal Edutech Undiksha. Retrieved from https://ejournal.undiksha.ac.id/index.php/JEU/article/view/1429/1290

Lee \& Owens (2004). Multimedia-Based Instructional Design. San Fransisco: Pfeiffer.

Mayer, R. E. (2001). Multimedia learning. Cambridge, UK: Cambridge University Press.

Miftah, M. (2013). Fungsi dan Peran Media Pembelajaran Sebagai Upaya Peningkatan Kemampuan Belajar Siswa. Jurnal Teknologi Pendidikan Kwangsan, 1 (2) 95-105. Retrieved from https://jurnalkwangsan.kemdikbud.go.id/index.php/jurnalkwangsan/article/view/7

Mustaqim, I. (2016). Pemanfaatan Augmented Reality Sebagai Media Pembelajaran. Jurnal Pendidikan Teknologi dan Kejuruan, 13 (2) 174-183. Retrieved from https://ejournal.undiksha.ac.id/index.php/JPTK/article/view/8525

Novianto, L. A., Degeng, S., Wedi, A. (2018). Pengembangan Multimedia Interaktif Mata Pelajaran IPA Pokok Bahasan Sistem Peredaran Darah Manusia Untuk Kelas VIII SMP Wahid Hasyim Malang. Jurnal Kajian Teknologi Pendidikan, 1 (3) 257-263. Retrieved form http://journal2.um.ac.id/index.php/jktp/article/view/5770/3414

Novita, D. (2016). Pengaruh Penggunaan Multimedia Interaktif Terhadap Kemampuan Pemahaman Konsep Matematis Siswa. Jurnal Pendidikan Matematika dan Matematika, 2 (2) 8-18. Retrieved from https://jurnal.umj.ac.id/index.php/fbc/article/view/1650

Praherdiono, Henry \& Adi, Eka Pramono. (2008). Panduan Praktikum Multimedia Malang: FIP UM.

Rorita, M. (2018). Pengembangan Multimedia Interaktif Berbasis Mobile Learning Pokok Bahasan Perkembangan Teori Atom Mata Pelajaran Kimia Kelas X SMA Panjura Malang. Jurnal Inovasi dan Teknologi Pembelajaran, 4 (2) 70-75. Retrieved form http://journal2.um.ac.id/index.php/jinotep/article/view/3765

Sarwiko, D. (2017). Pengembangan Media Pembelajaran Berbasis Multimedia Interaktif Menggunakan Macromedia Director MX. Jurnal online. Retrieved form http://journal2.um.ac.id/index.php/jo/article/view/4962 
Sudjana, N. (1991). Teori-Teori Belajar Untuk Pengajaran. Jakarta : FEUI http://jurnal.unej.ac.id/index.php/JEUJ/article/view/5206

Tafonao, T. (2018). Peranan Media Pembelajaran Dalam Meningkatkan Minat Belajar Mahasiswa. Jurnal Komunikasi Pendidikan, 2 (2) 103-114. Retrieved form http://journal.univetbantara.ac.id/index.php/komdik/article/view/113

Vaughan, T. (2004). Multimedia : Making It Works. Edisi VI. McGraw- Hill Compannies, Incorporated. USA: Beltsville.

Wiyono, K. (2012). Model Multimedia Interaktif Berbasis Gaya Belajar Untuk Meningkatkan Penguasaan Konsep Pendahuluan Fisika Zat Padat. Jurnal Pendidikan Fisika Indonesia, 8 (1) 74 82. Retrieved form https://journal.unnes.ac.id/nju 